\title{
The influence of high-carbohydrate meals with different glycaemic indices on substrate utilisation during subsequent exercise
}

\author{
Ching-Lin Wu, Ceri Nicholas, Clyde Williams*, Alison Took and Lucy Hardy \\ Sports and Exercise Nutrition Research Group, School of Sport and Exercise Sciences, Loughborough University, \\ Leicester, UK
}

(Received 28 October 2002 - Revised 9 July 2003 - Accepted 18 August 2003)

\begin{abstract}
The present study was designed to examine the effects of mixed high-carbohydrate meals with different glycaemic indices (GI) on substrate utilization during subsequent exercise. Nine healthy male recreational runners (age 26.8 (SEM 1.1) years, body mass 74.7 (SEM 2.4 ) $\mathrm{kg}, \dot{\mathrm{V}} \mathrm{O}_{2}$ max 58.1 (SEM 1.7) $\mathrm{ml} / \mathrm{kg}$ per min) completed three trials: high-glycaemic-index meal (HGI), low-glycaemic-index meal (LGI) and fasting (FAST), separated by $7 \mathrm{~d}$. The test meals contained $2 \mathrm{~g}$ carbohydrate/kg body mass, they were isoenergetic and the GI values were $77.4,36.9$ and 0.0 respectively. In each trial, subjects consumed the test meal $3 \mathrm{~h}$ before performing a $60 \mathrm{~min}$ run at $65 \% \dot{V} \mathrm{O}_{2}$ max on a motorized treadmill. Ingestion of the HGI and LGI resulted in hyperglycaemia and hyperinsulinaemia during the postprandial period compared with the FAST $(P<0 \cdot 05)$. The incremental area under the curve for plasma glucose was 2-fold higher for HGI compared with LGI (108.7 v. $48.9 \mathrm{mmol} / \mathrm{l}$ per $\mathrm{min})$. In contrast, plasma non-esterified fatty acid concentrations were significantly lower following HGI and LGI compared with FAST $(P<0 \cdot 05)$. During the subsequent submaximal exercise, plasma glucose declined to below the fasting value in HGI compared with LGI and FAST $(P<0 \cdot 05)$. The estimated total fat oxidation was significantly higher for the LGI than the HGI during exercise $(P<0.05)$. In summary, both pre-exercise carbohydrate meals resulted in lower rates of fat oxidation during subsequent exercise than when subjects performed exercise in the fasting state. However, the LGI resulted in a higher rate of fat oxidation during exercise than following the consumption of the HGI.
\end{abstract}

Glucose: Insulin: Fat oxidation: Carbohydrate oxidation

Ingestion of a high-carbohydrate (CHO) food before exercise can increase liver and muscle glycogen concentrations (Nilsson \& Hultman, 1973). It also affects the metabolic response and substrate utilization during subsequent exercise (Coyle 1997; Horowitz et al. 1997; Wee et al. 1999). Several studies have observed depressed rates of fat oxidation following ingestion of $\mathrm{CHO}$ (Coyle et al. 1997; Horowitz et al. 1997; Wee et al. 1999). This is mainly due to hyperinsulinaemia during the postprandial period (Coyle et al. 1997; Horowitz et al. 1997). Therefore, ingesting high-CHO foods before exercise without inducing high insulin secretion may cause a shift in substrate utilization toward fat oxidation during the subsequent submaximal exercise.

A number of studies have examined the influence of pre-exercise $\mathrm{CHO}$ ingestion on fat metabolism by using monosaccharides, disaccharides, oligosaccharides, whole food rich in $\mathrm{CHO}$ or the addition of the other macronutrients to a CHO source (Hargreaves et al. 1987; Ivy et al. 1988; Horowitz et al. 1997). Few studies have considered the effects of ingestion of foods of different glycaemic indices (GI) (Jenkins et al. 1981) before exercise (Thomas et al. 1991, 1994; Febbraio \& Stewart, 1996; Sparks et al. 1998; DeMarco et al. 1999; Wee et al. 1999; Febbraio et al. 2000b; Kirwan et al. 2001a). Thomas et al. (1991) first reported that the ingestion of a single low-GI food $45 \mathrm{~min}$ before exercise improved endurance capacity on a cycle ergometer compared with that of a single high-GI food. Nevertheless, subsequent studies have not shown differences in performance between the two types of foods (Thomas et al. 1994; Febbraio \& Stewart, 1996; Sparks et al. 1998; Wee et al. 1999; Febbraio et al. 2000b). The inconsistency in the results may be due to the difference in the timing of food ingestion, the quantity of $\mathrm{CHO}$ ingested and the type of exercise employed. However, these studies demonstrated that the ingestion of low-GI foods before submaximal exercise reduces postprandial glycaemia and insulinaemia. This is accompanied by higher concentrations of plasma non-esterified fatty acids (NEFA) during exercise compared with the responses to a high-GI food (Thomas et al. 1994; Febbraio \& Stewart, 1996;

\footnotetext{
Abbreviations: CHO, carbohydrate; FAST, water only meal; GI, glycaemic index; HGI, high-glycaemic-index meal; LGI, low-glycaemic-index meal; NEFA, non-esterified fatty acid; $\dot{V} \mathrm{O}_{2}$ max, maximal oxygen uptake.

* Corresponding author: Professor Clyde Williams, fax + 441509 226300, email C.Williams@lboro.ac.uk
} 
Sparks et al. 1998; Wee et al. 1999; Febbraio et al. $2000 a, b)$ These responses favour higher rates of fat oxidation than is the case following the consumption of a high-GI meal (Thomas et al. 1994; Febbraio \& Stewart, 1996; Wee et al. 1999; Sparks et al. 1998; DeMarco et al. 1999; Febbraio et al. 2000a,b). The metabolic changes following ingestion of a single GI food seemed clear; however, it is not customary to consume single GI foods in daily life. A method for calculating the GI of mixed meals has been proposed by Wolever \& Jenkins (1986). Research into the metabolic responses to a mixed meal containing foods with different GI values is much needed. Therefore, the aim of the present study was to compare two meals with different GI on substrate utilization during subsequent exercise.

\section{Methods}

Nine male recreational runners, aged $26 \cdot 8$ (SEM $1 \cdot 1$ ) years, body mass 74.7 (SEM 2.4) kg, $\dot{V} \mathrm{O}_{2} \max 58.1$ (SEM 1.7) $\mathrm{ml} /$ $\mathrm{kg}$ per min, participated in the present study. The protocol was approved by Loughborough University Ethical Advisory Committee and all subjects gave their written informed consent.

\section{Preliminary measurements}

Two preliminary tests were undertaken before three main trials: these were to determine the maximal $\mathrm{O}_{2}$ uptake $\left(\dot{V} \mathrm{O}_{2} \max \right)$ of each subject and the relationship between submaximal running speed and $\mathrm{O}_{2}$ uptake (Williams et al. 1990). An uphill treadmill running test was used to determine the $\dot{V} \mathrm{O}_{2}$ max of each subject. The speed of the treadmill (Technogym, Gambettola, Italy) was kept constant throughout the test and the inclination was increased from an initial $3.5 \%$ by $2.5 \%$ every 3 min until the subjects reached volitional fatigue. Expired gas was collected by the Douglas bag method for $1 \mathrm{~min}$ in each $3 \mathrm{~min}$ period and also when the subjects signalled that the running speed could only be sustained for a final minute. A 16 min continuous submaximal test was employed to determine the relationship between submaximal running speed and $\dot{V} \mathrm{O}_{2}$, consisting of four stages. The initial speed of treadmill was set between 8.0 and $9.0 \mathrm{~km} / \mathrm{h}$ depending on the subject's training status. The treadmill speed was increased every $4 \mathrm{~min}$ by 1.0 to $1.5 \mathrm{~km} / \mathrm{h}$. Expired gas samples were collected during the last minute of each stage for the determination of $\dot{V} \mathrm{O}_{2}$. A regression equation was calculated for the relationship between $\dot{V} \mathrm{O}_{2}$ and running speed from the results of the $16 \mathrm{~min}$ test. One week before the main trial, the subjects were asked to complete a $30 \mathrm{~min}$ run at $65 \% \quad \dot{V} \mathrm{O}_{2}$ max in order to confirm the relative exercise intensity and fully familiarize them with treadmill running and the experimental procedures.

\section{Test meal}

Subjects were provided with one of three test meals. They were: (1) a high-GI meal (HGI); (2) a low-GI meal (LGI); (3) water (FAST). The HGI and the LGI meals provided $2 \mathrm{~g} \mathrm{CHO} / \mathrm{kg}$ body mass with different GI, were isoenergetic and had the same macronutrient composition. The HGI meal consisted of Corn Flakes (Kellogg's (UK) Ltd, Manchester, UK), skimmed milk, white bread, jam, a highCHO drink (Lucozade original; GlaxoSmithKline, Brentwood, London, UK) and water, with an overall GI of 77.4. The LGI meal, with a GI of $36 \cdot 9$, consisted of All Bran ${ }^{\text {TM }}$ (Kellogg's (UK) Ltd), skimmed milk, peaches, apples and apple juice. Wolever \& Jenkins' (1986) method of GI calculation was used, with GI values taken from Foster-Powell \& Miller's (1995) GI table. In the FAST trial, subjects consumed a volume of water equal to the amount of fluid given in the HGI and LGI trials. Table 1 shows the composition of each test meal.

\section{Experimental design}

All subjects completed three experimental trials, each separated by 1 week. Subjects consumed the test meals described earlier $3 \mathrm{~h}$ before a $60 \mathrm{~min}$ run at $65 \% \dot{\mathrm{V}} \mathrm{O}_{2} \max$ on a motorized treadmill. A counterbalance design was applied to this study and the order of the trials was randomized.

All trials were performed in the Exercise Physiology Laboratory in the School of Sport and Exercise Sciences at Loughborough University under similar experimental and environmental conditions. The subjects were instructed to refrain from heavy physical activities and to consume exactly the same diet for $2 \mathrm{~d}$ before each main trial. All subjects were also asked to abstain from alcohol, caffeine and tobacco consumption for $24 \mathrm{~h}$ before each main trial.

\section{Protocol}

On the day of the experiment, subjects reported to the laboratory after a $12 \mathrm{~h}$ overnight fast. The subjects were asked to void before nude body mass was obtained. After weighing, a cannula was inserted into an antecubital vein while the subject was lying on an examination

Table 1. Characteristics of test meals (for $70 \mathrm{~kg}$ subject)

\begin{tabular}{|c|c|c|}
\hline Meal & Description & Macronutrient content \\
\hline HGI & $\begin{array}{l}60 \mathrm{~g} \text { Corn Flakes }+280 \mathrm{ml} \text { skimmed milk }+77 \mathrm{~g} \text { white bread } \\
+20 \mathrm{~g} \text { raspberry jam }+167 \mathrm{ml} \text { Lucozade original drink }{ }^{*}+400 \mathrm{ml} \text { water }\end{array}$ & $\begin{array}{l}2.79 \mathrm{MJ}, 141 \mathrm{~g} \mathrm{CHO}, 20 \mathrm{~g} \text { protein, } 3 \mathrm{~g} \text { fat, } 820 \mathrm{ml} \text { water } \\
\text { (estimated } \mathrm{Gl} 77.4 \dagger \text { ) }\end{array}$ \\
\hline FAST & $820 \mathrm{ml}$ water & OMJ (estimated GI 0†) \\
\hline
\end{tabular}

HGI, high-glycaemic-index meal; LGI, low-glycaemic-index meal; FAST, water only; CHO, carbohydrate; GI, glycaemic index.

${ }^{*}$ Corn Flakes, All Bran ${ }^{\mathrm{TM}}$ : Kellogg's (UK) Ltd, Manchester, UK; Lucozade original drink, UK.

† Calculated by the method described by Wolver \& Jenkins (1986) with Gl values taken from Foster-Powell \& Brand Miller (1995). 
couch. A short-range telemeter (Sports Tester PE3000; Polar Electro, Kempele, Finland) was then attached to the subject to monitor the heart rate.

Basal blood and gas samples were obtained after the subject had sat for $10 \mathrm{~min}$. The test meal was then served and the subject was asked to consume it within $20 \mathrm{~min}$. After finishing the test meal, the $3 \mathrm{~h}$ postprandial period began. During the postprandial period, subjects were asked to remain seated, avoiding any physical activity.

Ambient temperature and relative humidity were recorded at $30 \mathrm{~min}$ intervals during the postprandial period and at $15 \mathrm{~min}$ intervals during exercise, using a hydrometer (Zeal, London, UK). Temperature was maintained at $20-25^{\circ} \mathrm{C}$ and humidity was $50-60 \%$ in all trials. While running on the treadmill, subjects were cooled by electric fans and wet sponges were also available for use ad libitum.

\section{Blood sample collection and analysis}

Blood samples were obtained from a cannula (Venflon 18G; Becton Dickinson Ltd, Helsingborg, Sweden) in the antecubital vein; the cannula was connected to a three-way stopcock (Connecta Ltd, Helsingborg, Sweden) with a $100 \mathrm{~mm}$ extension tube. The cannula was frequently flushed with sterile $\mathrm{NaCl}$ solution $(9 \mathrm{~g} / \mathrm{l})$ to keep it patent throughout the experiment. Blood samples were obtained with subjects in the sitting position during the postprandial period. In addition to the basal blood sample, further samples were obtained at 15, 30, 60, 90, 120 and 180 min during the postprandial period, and at $15 \mathrm{~min}$ intervals during the subsequent exercise.

Blood $(10 \mathrm{ml})$ was collected at each sampling time. Haemoglobin concentration was determined by the cyanmethaemoglobin method (Boehringer Mannheim, Mannheim, Germany). Packed cell volumes were determined in triplicate on samples of whole blood by microcentrifugation (Hawksley Ltd, Lancing, Sussex, UK). Changes in plasma volume were estimated from changes in haemoglobin concentrations and packed cell volumes (Dill \& Costill, 1974). A duplicate $20 \mu$ l blood sample was deproteinized in $200 \mu \mathrm{l}$ perchloric acid $(25 \mathrm{ml} / \mathrm{l})$ and then centrifuged for $3 \mathrm{~min}$ at $10250 \mathrm{~g}$ before being frozen at $-20^{\circ} \mathrm{C}$ for later analysis of lactate (Maughan, 1982) using a fluorometer (model 8-9; Locarte, London, UK). A $5 \mathrm{ml}$ blood sample was put into an EDTA tube and centrifuged (Burkard Ltd, Uxbridge, Middlesex, UK) at $1500 \mathrm{~g}$ for $10 \mathrm{~min}$ to obtain plasma for analysis of NEFA (ACSACOD method, Wako NEFA C; Wako, Neuss, Germany) and glucose (GOD-PAP method, Boehringer Mannheim) using an automatic photometric analyser (Cobas-Mira; Roche, Basel, Switzerland). Plasma glycerol concentrations were analysed using a fluorometric method (Laurell \& Tibbling, 1966). The remaining blood (about $5 \mathrm{ml}$ ) was placed into a non-heparinized tube and left to clot for $1 \mathrm{~h}$. Serum samples were then obtained after centrifugation (Burkard Ltd) at $1500 \mathrm{~g}$ for $10 \mathrm{~min}$. The serum was stored in portions at $-70^{\circ} \mathrm{C}$ and later analysed for insulin by radioimmunoassay (Coat-Count Insulin; ICN Ltd, Eschwege, Germany), using a $\gamma$-counter (Cobra 5000; Packard Ltd, Boston, MA, USA).

\section{Expired gas sample collection and analysis}

Samples of expired gas were collected using the Douglas bag method at the following times: pre-meal, during the postprandial period $(15,30,60,90,120,150$ and $180 \mathrm{~min}$ ) and every $15 \mathrm{~min}$ during exercise. Each expired gas sample was collected through a one-way low-resistance valve and a lightweight, wide-bore tubing (Falconia Baxter Woodhouse \& Taylor Ltd, Macclesfield, Cheshire, UK) into a Douglas bag for $5 \mathrm{~min}$ during the resting collections and for $1 \mathrm{~min}$ during exercise. $\mathrm{O}_{2}$ and $\mathrm{CO}_{2}$ content were analysed using methods previously described (Williams et al. 1990). The energy expenditure, and total CHO and fat oxidation rates, were estimated from $\dot{V} \mathrm{O}_{2}$ and $\dot{V} \mathrm{CO}_{2}$ by using stoichiometric equations (Frayn, 1983):

$$
\begin{aligned}
\mathrm{CHO} \text { oxidation rate }(\mathrm{g} / \mathrm{min})= & 4.585 \times \dot{\mathrm{V}} \mathrm{CO}_{2} \\
& -3.226 \times \dot{\mathrm{V}} \mathrm{O}_{2}
\end{aligned}
$$

and

fat oxidation rate $(\mathrm{g} / \mathrm{min})=1.695 \times \dot{V} \mathrm{O}_{2}$

$$
-1.701 \times \dot{V} \mathrm{CO}_{2} \text {. }
$$

Total $\mathrm{CHO}$ and fat oxidation was estimated from the area under the rate of oxidation $v$. time curve for each subject. The ratings of perceived exertion (Borg, 1973), perceived thirst and gut fullness were recorded using 6-20 scales.

\section{Statistical analyses}

Data were analysed by using a statistics software package SPSS for Windows, version 10.0 (SPSS Inc., Chicago, IL, USA). A two-way (time $\times$ treatment) ANOVA with repeated measures was used to analyse overall differences in the physiological and biochemical responses to the three main trials. When a significant difference was found, Tukey's post hoc test was used to locate the differences in mean values. For non-time dependent variables, Student's $t$ test for paired observations was used. Significance was set at the 0.05 level of confidence. Results are presented as mean values with their standard errors.

\section{Results}

\section{Plasma glucose and serum insulin}

Following ingestion of the HGI and LGI meals, plasma glucose concentration increased sharply and peaked at 15 min during the postprandial period (6.8 (SEM 0.5) and $6 \cdot 2$ (SEM 0.3) mmol/l respectively, Fig. 1). Thereafter, plasma glucose decreased below the FAST concentration after $60 \mathrm{~min}$ in the LGI (FAST 4.5 (SEM 0.2), LGI 4.13 (SEM 0.22 ) $\mathrm{mmol} / \mathrm{l}$ ) and after $180 \mathrm{~min}$ in the HGI trial (FAST 4.5 (SEM 0.2), LGI 3.9 (SEM 0.2) mmol/1). Fifteen minutes after the start of exercise, plasma glucose further declined to 3.5 (SEM 0.1) and 4.1 (SEM 0.1) $\mathrm{mmol} / \mathrm{l}$ in the HGI and LGI trials respectively.

The serum insulin concentration peaked at $15 \mathrm{~min}$ in the LGI trial, and at $30 \mathrm{~min}$ in the HGI trial, after ingestion of the meals (139.4 (SEM 18.4) and 131.0 (SEM 22.8) mIU/l respectively, Fig. 2). The concentrations were significantly higher than in the FAST trial in the first $2 \mathrm{~h}$ during the 


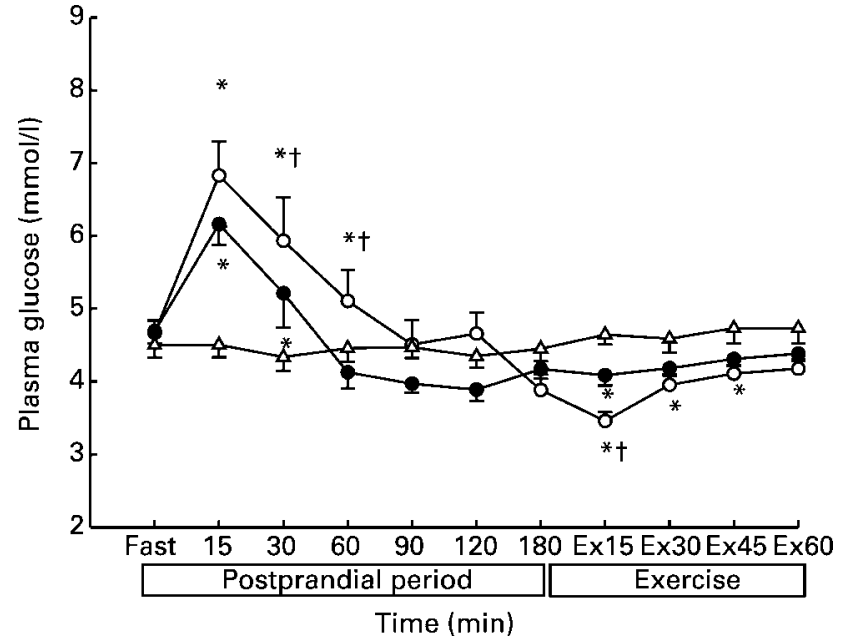

Fig. 1. Effect of a high-glycaemic-index meal (HGI; O), low-glycaemic-index meal (LGI; $\bullet$ ) or water only (FAST; $\triangle$ ) on plasma glucose concentration during a postprandial (resting) period and exercise (Ex). For details of meals, subjects and procedures, see Table 1 and p. 1050. Values are means with their standard errors shown by vertical bars $(n 9)$. Mean values were significantly different from those of FAST: ${ }^{\star} P<0.05$. Mean values were significantly different from those of LGI: $\dagger P<0.05$.

postprandial period in both the HGI and LGI trials $(P<0 \cdot 05)$. Thereafter, serum insulin concentration decreased, such that it was similar to the fasting concentration.

The incremental areas under the curve over the postprandial period for both glucose (108.7 v. $48.9 \mathrm{mmol} / \mathrm{l}$ per min) and insulin (12146 v. 8654 IU/l per $\mathrm{min}$ ) were higher during the HGI than LGI trial. The HGI:LGI plasma glucose incremental area under the curve was $2 \cdot 2: 1 \cdot 0$, which was similar to the estimated GI ratio of $2 \cdot 1: 1 \cdot 0$.

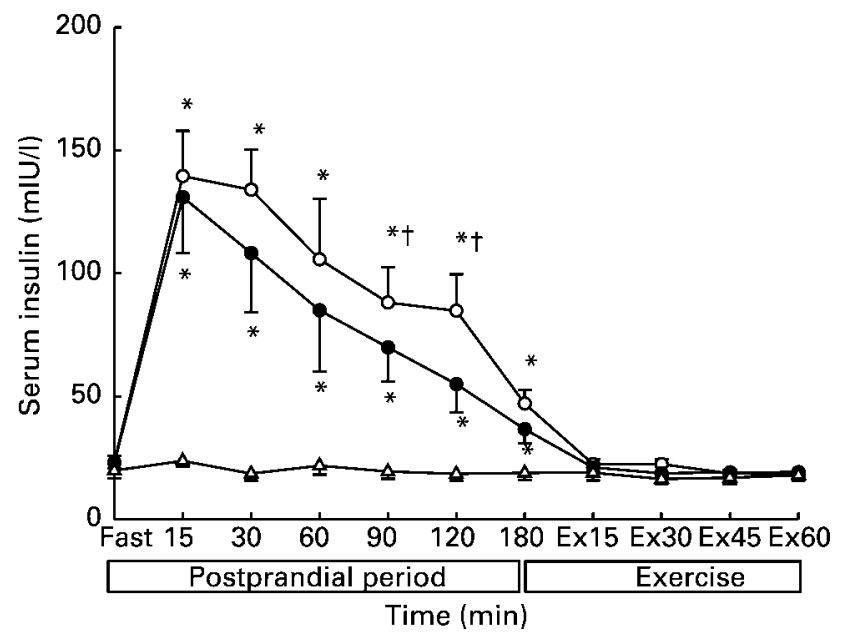

Fig. 2. Effect of a high-glycaemic-index meal (HGl; O), low-glycaemic-index meal $(\mathrm{LGl} ; \bullet)$ or water only (FAST; $\triangle$ ) on plasma insulin concentration during a postprandial (resting) period and exercise (Ex). For details of meals, subjects and procedures, see Table 1 and p. 1050. Values are means with their standard errors shown by vertical bars $(n 9)$. Mean values were significantly different from those of FAST: ${ }^{*} P<0.05$. Mean values were significantly different from those of $\mathrm{LGI}: \dagger P<0.05$.

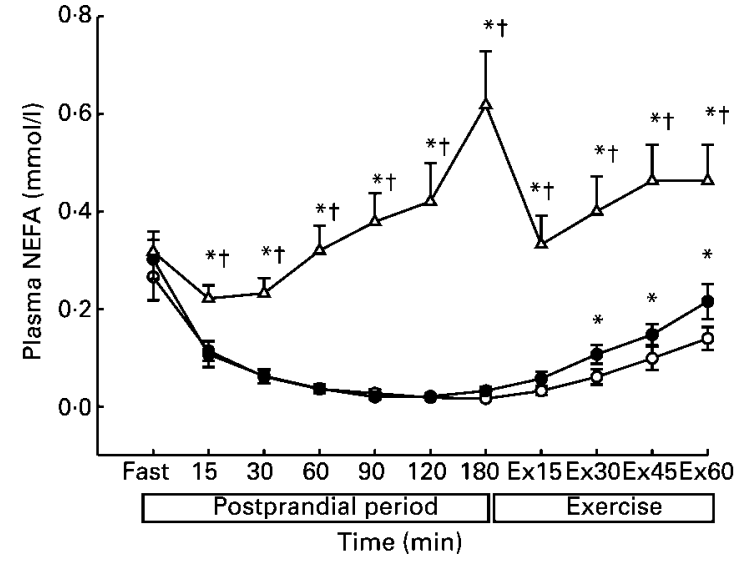

Fig. 3. Effect of a high-glycaemic-index meal (HGI; O), low-glycaemic-index meal (LGI; $\bullet$ ) or water only (FAST; $\triangle$ ) on plasma nonesterified fatty acid (NEFA) concentration during a postprandial (resting) period and exercise (Ex). For details of meals, subjects and procedures, see Table 1 and p. 1050. Values are means with their standard errors shown by vertical bars $(n 9)$. Mean values were significantly different from those of $\mathrm{HGl}$ : ${ }^{*} P<0.05$. Mean values were significantly different from those of $L G I: \dagger P<0.05$.

\section{Plasma non-esterified fatty acids and glycerol}

Plasma NEFA concentrations were suppressed following the HGI and LGI meals compared with the FAST trial (Fig. 3). The FAST trial NEFA concentrations were higher from $60 \mathrm{~min}$ into the postprandial period to the end of the exercise $(P<0 \cdot 05)$. At the onset of exercise, plasma NEFA increased gradually throughout the exercise period in both the HGI and LGI trials. Although plasma NEFA concentrations were higher in the LGI trial than the HGI trial during exercise $(P<0 \cdot 05)$, they remained lower than the values in the FAST trial $(P<0 \cdot 05)$.

Plasma glycerol showed a similar response to that of plasma NEFA (Fig. 4). In the FAST trial plasma glycerol

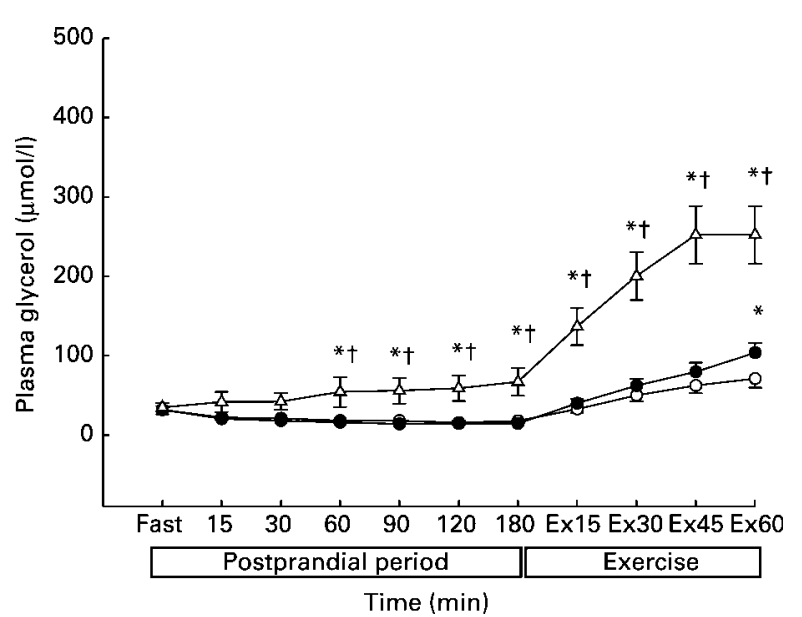

Fig. 4. Effect of a high-glycaemic-index meal (HGl; O), low-glycaemic-index meal (LGl; $\bullet$ ) or water only (FAST; $\triangle$ ) on plasma glycerol concentration during a postprandial (resting) period and exercise (Ex). For details of meals, subjects and procedures, see Table 1 and p. 1050. Values are means with their standard errors shown by vertical bars $(n 9)$. Mean values were significantly different from those of $\mathrm{HGl}$ : ${ }^{*} P<0.05$. Mean values were significantly different from those of $\mathrm{LGI}: \dagger P<0.05$. 
concentrations were higher from 60 min into the postprandial period to the end of the exercise $(P<0.05)$. At the onset of exercise, plasma glycerol concentrations increased gradually throughout the exercise period in both the HGI and LGI trials. There were no significant differences in plasma glycerol concentrations between the two meal trials during the postprandial period; however, at $60 \mathrm{~min}$ of exercise, the glycerol concentration was higher during the LGI trial than in the HGI trial $(P<0.05)$.

\section{Blood lactate}

Following the ingestion of LGI and HGI meals, blood lactate concentrations increased significantly $(P<0.05)$, peaking at $30 \mathrm{~min}$ during the postprandial period (Fig. 5). Blood lactate concentration was significantly higher in the first $2 \mathrm{~h}$ during the postprandial period in the LGI than in the HGI and FAST trials $(P<0.05)$. However, at the start of exercise, blood lactate values had returned to resting concentrations in HGI and LGI trials. During exercise, blood lactate increased sharply in all trials. However, there was no significant difference between trials.

\section{Estimated carbohydrate and fat oxidation rates}

The estimated total amount of $\mathrm{CHO}$ oxidized was significantly higher in the HGI and LGI trials than in the FAST trial during the $3 \mathrm{~h}$ postprandial period (HGI 51.8 (SEM 3.2), LGI 52.8 (SEM 3.8), FAST 22.7 (SEM 5.4) g/3 h; Fig. $6, P<0.01)$. In contrast, the calculated total amount of fat oxidized was lower in the HGI and LGI trials compared with FAST trials during the postprandial period (HGI 9.5 (SEM 1.0), LGI 9.9 (SEM 1.0), FAST 17.5 (SEM 1.6); Fig. 7, $\mathrm{P}<0.05)$.

A higher fat oxidation rate and lower $\mathrm{CHO}$ oxidation rate were observed in the FAST compared with the HGI

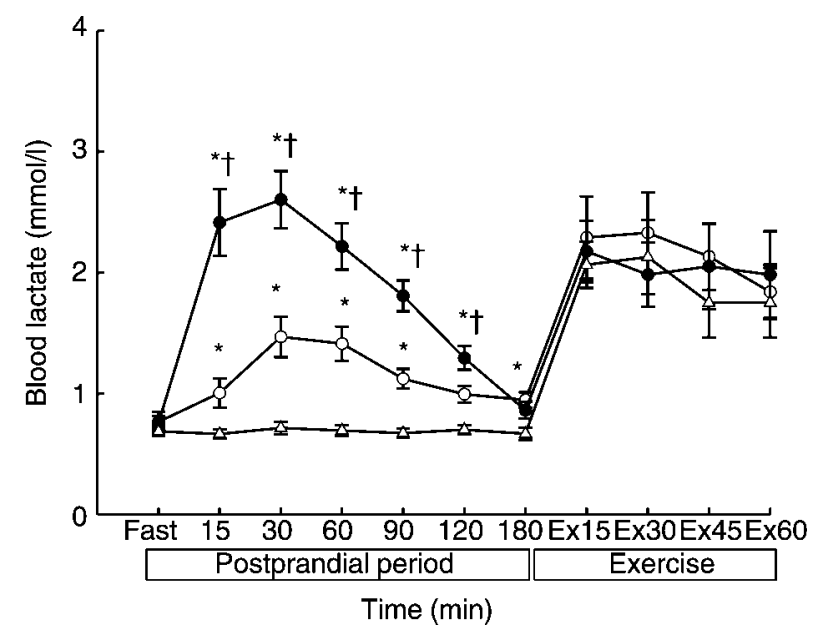

Fig. 5. Effect of a high-glycaemic-index meal (HGI; O), low-glycaemic-index meal (LGI; •) or water only (FAST; $\triangle$ ) on plasma lactate concentration during a postprandial (resting) period and exercise (Ex). For details of meals, subjects and procedures, see Table 1 and p. 1050. Values are means with their standard errors shown by vertical bars $(n 9)$. Mean values were significantly different from those of FAST: ${ }^{\star} P<0.05$. Mean values were significantly different from those of $\mathrm{HGl}: \dagger P<0.05$.

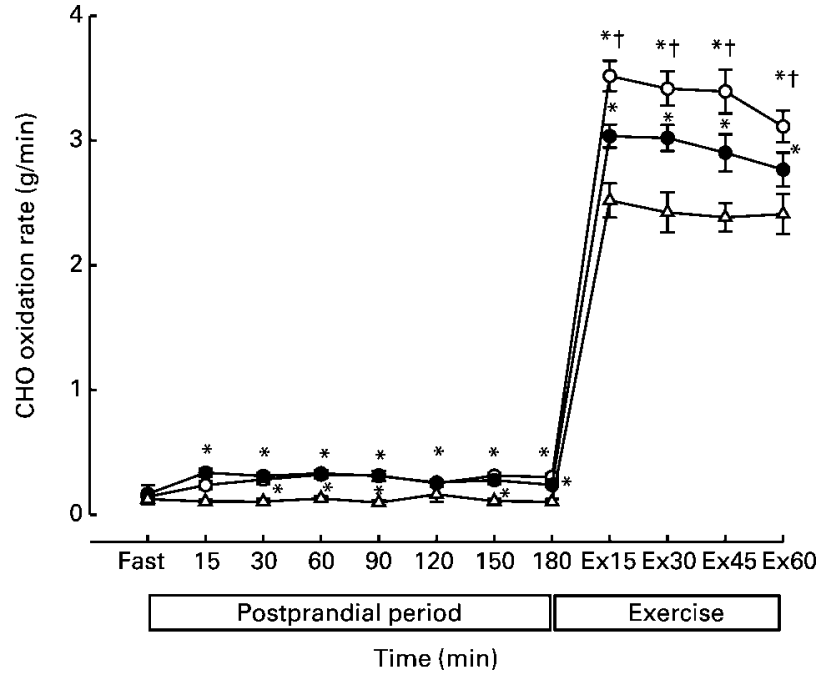

Fig. 6. Effect of a high-glycaemic-index meal (HGl; O), low-glycaemic-index meal (LGI; $\bullet$ ) or water only (FAST; $\triangle$ ) on the rate of carbohydrate $(\mathrm{CHO})$ oxidation during a postprandial (resting) period and exercise (Ex). For details of meals, subjects and procedures, see Table 1 and p. 1050. Values are means with their standard errors shown by vertical bars ( $n 9)$. Mean values were significantly different from those of FAST: ${ }^{\star} P<0.05$. Mean values were significantly different from those of LGI: $\dagger P<0.05$.

and LGI trials during exercise (fat 28.6 (SEM 4.4), CHO $146.0($ SEM $8 \cdot 2) \mathrm{g} / \mathrm{h}$; Figs 6 and $7, P<0.05)$. The respiratory exchange ratio values were lower during postprandial period and exercise in the FAST than in LGI and HGI trials (Table 2, $P<0 \cdot 05$ ). There was also a trend for lower respiratory exchange ratio values in LGI compared with HGI $(P=0 \cdot 09)$. However, there were differences in the calculated rates of fat and $\mathrm{CHO}$ oxidation (Figs 6 and 7, $P<0 \cdot 05$ ) (Frayn, 1983). There was greater fat oxidation

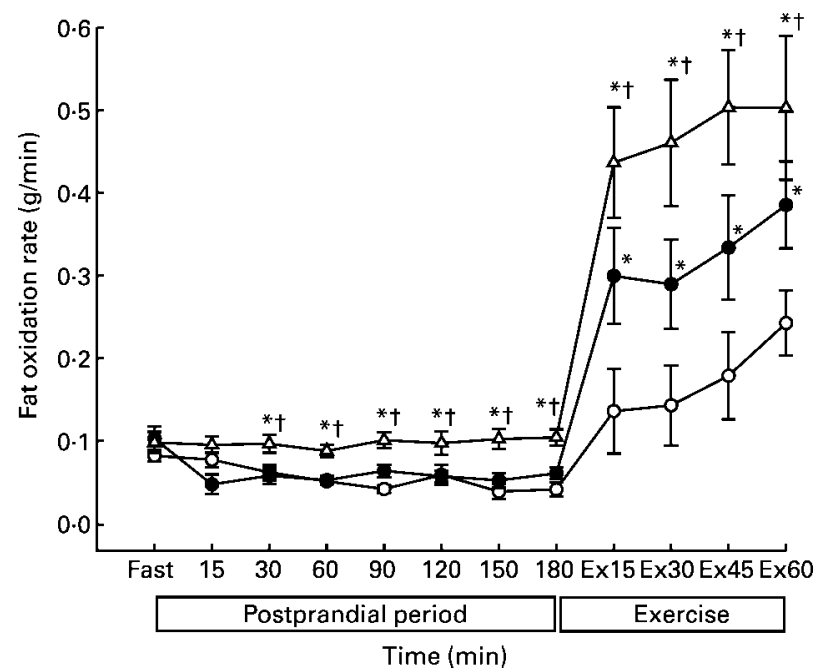

Fig. 7. Effect of a high-glycaemic-index meal (HGl; O), low-glycaemic-index meal (LGI; $\bullet$ ) or water only (FAST; $\triangle$ ) on the rate of fat oxidation during a postprandial (resting) period and exercise (Ex). For details of meals, subjects and procedures, see Table 1 and p. 1050. Values are means with their standard errors shown by vertical bars $(n 9)$. Mean values were significantly different from those of $\mathrm{HGI}:{ }^{*} P<0.05$. Mean values were significantly different from those of LGI: $† P<0.05$. 
Table 2. Oxygen uptake $\left(\mathrm{VO}_{2}\right)$, carbon dioxide expired $\mathrm{VCO}_{2}$ and the respiratory exchange ratio (RER) during high-glycaemic-index meal (HGI), low-glycaemic-index meal (LGI) and water only (FAST) trialst

(Mean values with their standard errors)

\begin{tabular}{|c|c|c|c|c|c|c|c|}
\hline \multirow[b]{2}{*}{ Variable } & \multirow[b]{2}{*}{ Meal } & \multicolumn{2}{|c|}{ Resting } & \multicolumn{2}{|c|}{$\begin{array}{l}\text { Postprandial } \\
\text { period }\end{array}$} & \multicolumn{2}{|c|}{$\begin{array}{c}\text { Exercise } \\
\text { period }\end{array}$} \\
\hline & & Mean & SEM & Mean & SEM & Mean & SEM \\
\hline \multirow[t]{3}{*}{$\mathrm{VO}_{2}(\mathrm{l} / \mathrm{min})$} & HGI & 0.27 & 0.01 & $0.31^{*}$ & 0.01 & 2.79 & 0.10 \\
\hline & LGI & 0.28 & 0.01 & $0.32^{*}$ & 0.01 & $2 \cdot 82$ & 0.10 \\
\hline & FAST & 0.28 & 0.01 & 0.27 & 0.01 & $2 \cdot 77$ & 0.10 \\
\hline \multirow[t]{3}{*}{$\dot{\mathrm{V} C O}{ }_{2}(\mathrm{l} / \mathrm{min})$} & $\mathrm{HGI}$ & 0.22 & 0.01 & $0 \cdot 28^{*}$ & 0.01 & $2 \cdot 70^{*}$ & 0.08 \\
\hline & LGI & 0.23 & 0.02 & $0.29^{*}$ & 0.01 & $2 \cdot 62^{*}$ & 0.08 \\
\hline & FAST & 0.22 & 0.01 & 0.22 & 0.01 & 2.48 & 0.10 \\
\hline \multirow[t]{3}{*}{ RER } & $\mathrm{HGI}$ & 0.82 & 0.02 & $0.90^{\star}$ & 0.01 & $0.96^{*}$ & 0.01 \\
\hline & LGI & 0.81 & 0.03 & $0.90^{*}$ & 0.01 & $0.94^{*}$ & 0.01 \\
\hline & FAST & 0.79 & 0.03 & 0.79 & 0.02 & 0.90 & 0.01 \\
\hline
\end{tabular}

Mean values were significantly different from those of FAST: ${ }^{\star} P<0.05$.

†For details of meals, subjects and procedures, see Table 1 and p. 1050.

and less $\mathrm{CHO}$ oxidation in the LGI trial than in the HGI trial during exercise (fat: HGI $10 \cdot 5$ (SEM 2.7), LGI $19 \cdot 3$ (SEM 3.2); CHO: HGI 201.5 (SEM 6.5), LGI $175 \cdot 8$ (SEM 6.6) $\mathrm{g} / \mathrm{h}$; Figs 6 and $7, P<0.05)$.

\section{Plasma volume}

There was a significant decrease in plasma volume during exercise in all three trials (HGI 8.9, LGI 11.9, FAST $11.6 \% ; P<0.05)$; however, there were no differences between the three trials.

\section{Heart rate and rate of perceived exertion}

There were no significant differences in heart rate or rate of perceived exertion between the three trials (Table 3 ).

\section{Gut fullness and thirst scales}

Following ingestion of the HGI and LGI meals, the perception of gut fullness significantly increased compared with that in the FAST trial $(P<0 \cdot 05$, Table 3$)$. The peak value occurred $15 \mathrm{~min}$ after the meal in both trials and it remained higher than the FAST trial during the postprandial period $(P<0 \cdot 05)$. There were no significant differences in the ratings of thirst between the three trials (Table 3).

\section{Discussion}

The main finding from the current study was that the calculated amount of fat oxidation was significantly higher during exercise commencing $3 \mathrm{~h}$ after consuming a LGI meal compared with the fat oxidation after a HGI meal. The results also demonstrated that the HGI meal resulted in a greater glycaemic and insulinaemic response during the postprandial period compared with the LGI meal. Several studies have reported a higher rate of fat oxidation after ingesting single low-GI foods during subsequent submaximal exercise (Thomas et al. 1994; Febbraio \& Stewart, 1996; Wee et al. 1999). However, there appear

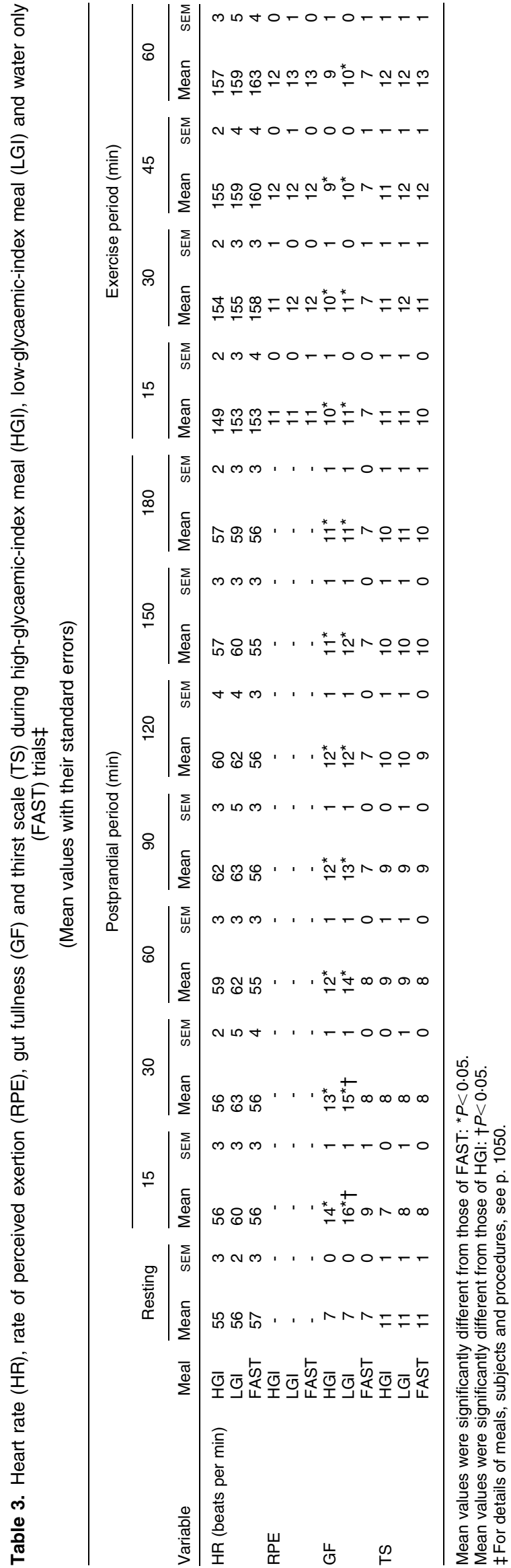


to be no reported studies on fat oxidation rates in response to low-GI meals in relation to fasting.

The GI concept is based on the incremental area under the blood glucose curve following the ingestion of $\mathrm{CHO}-$ rich foods compared with that of a reference food, i.e. glucose or white bread (Jenkins et al. 1981). The validity of the GI values for mixed meals has been questioned in several studies (Coulston et al. 1984a,b; Hollenbeck et al. 1988). In the present study, subjects consumed $2 \mathrm{~g}$ $\mathrm{CHO} / \mathrm{kg}$ body mass, approximately three times the amount of $\mathrm{CHO}$ used in the standard GI test $(50 \mathrm{~g} \mathrm{CHO})$. However, the estimated GI ratio of the two test meals in the present study was $2 \cdot 1: 1 \cdot 0(77 \cdot 4 / 36 \cdot 9)$, which is similar to the actual measured value of $2 \cdot 2: 1 \cdot 0$. This offers support for calculation of the GI values for mixed meals suggested by Wolever \& Jenkins (1986).

Although the serum insulin incremental area under the blood glucose curve was higher in the HGI trial than in the LGI, the magnitude of the insulinaemic response was not as pronounced as between the HGI and LGI meals in previous studies (Thomas et al. 1991, 1994; Febbraio \& Stewart, 1996; Sparks et al. 1998; Wee et al. 1999). In the current study, insulin concentration peaked at $15 \mathrm{~min}$ following the ingestion of both the HGI and LGI meals. This observation has not been reported in previous studies, possibly because single foods rather than meals were used (Thomas et al. 1991, 1994; Febbraio \& Stewart, 1996; Sparks et al. 1998; Wee et al. 1999). Some earlier studies observed a linear correlation between the GI and insulinaemic index (Wolever \& Bolognesi, 1996; Bjorck et al. 2000), which was not observed in the early stage of postprandial period in the present study. However, several studies have indicated that additional protein, especially dairy products, in a $\mathrm{CHO}$-containing meal could stimulate higher insulin secretion (Burke et al. 1995; Tarnopolsky et al. 1997). In the current study, both test meals contained skimmed milk, classified as a low-GI food, but which may induce insulinaemia during the postprandial period (Bjorck et al. 2000). The high insulin responses in the LGI trial may also explain the rapid decrease in the plasma glucose concentration during the early postprandial period.

Interestingly, blood lactate was elevated during the postprandial period following the ingestion of the HGI and LGI meals. Indeed in the LGI trial, blood lactate concentration peaked at $2.6 \mathrm{mmol} / 1$, a value approximately fourfold higher than the resting values. Several studies have shown elevated lactate concentrations following the ingestion of CHO-containing foods (Wee et al. 1999; Stannard et al. 2000). Although the mechanism is unclear, high lactate concentrations following the ingestion of fructose solutions have been reported in other studies (Decombaz et al. 1985; Fielding et al. 1987; Hargreaves et al. 1987; Murray et al. 1989a,b; Ventura et al. 1994). In the current study, the LGI meal contained more fructose $(26 \mathrm{~g} / 70 \mathrm{~kg}$ man) than the HGI meal ( $4 \mathrm{~g} / 70 \mathrm{~kg}$ man); this may explain the higher blood lactate concentration in the LGI trial during the postprandial period. The proportion of fructose and glucose contents of the meals was $<20 \%$ of the energy content of the meals. During exercise there were no differences in the blood lactate concentrations during the two trials.
A higher rate of fat oxidation was observed in the LGI compared with the HGI during exercise in the present study: this confirms the results of an earlier study (Wee et al. 1999). The exercise intensity that elicits the maximal rate of fat oxidation was recently reported as being approximately $64 \% \quad \dot{V} \mathrm{O}_{2} \max$ (Achten et al. 2002), and this was very close to the intensity used in the present study $\left(65 \% \quad \dot{V} \mathrm{O}_{2} \max \right)$. However, this exercise intensity may be somewhat different when subjects are fed rather than fasting, because pre-exercise ingestion of $\mathrm{CHO}$ suppresses fat oxidation. The exercise intensity that stimulates optimum fat oxidation in fed rather than in fasting individuals has yet to be reported. Nevertheless, fasting and exercise are the most effective ways of increasing fat oxidation. The observation that $\mathrm{CHO}$ ingestion results in the reduction in fat oxidation has been reported in several studies (Coyle et al. 1997; Horowitz et al. 1997). However, low-GI CHO induces lower insulin secretion during postprandial period, and this may be accompanied by a reduced suppression of fat oxidation during subsequent exercise. Therefore, ingestion of a low-GI high-CHO meal may provide the $\mathrm{CHO}$ required during subsequent exercise without depressing fat oxidation to the same extent as is the case when a high-GI $\mathrm{CHO}$ meal is consumed before exercise. More recently, it has been reported that following the ingestion of a medium-GI food, muscle glycogen used during subsequent exercise was similar to that in the control (fasting) trial (Kirwan et al. 2001b). Although muscle glycogen concentration was not measured in the present study, it is reasonable to speculate that the higher fat oxidation may spare muscle glycogen during exercise and may also contribute to an increased loss of body fat mass.

In summary, ingestion of pre-exercise $\mathrm{CHO}$ meals resulted in lower rates of fat oxidation during subsequent exercise $\left(\begin{array}{lll}65 \% & \dot{V} \mathrm{O}_{2} \max \end{array}\right)$ than when subjects performed exercise in the fasting state. However, the low-GI meal resulted in a higher rate of fat oxidation during exercise than following the consumption of the high-GI meal.

Furthermore, the greater rate of fat oxidation in the LGI meal may be beneficial in improving endurance performance in men by delaying the depletion of muscle glycogen.

\section{References}

Achten J, Gleeson M \& Jeukendrup AE (2002) Determination of the exercise intensity that elicits maximal fat oxidation. Med Sci Sports Exerc 34, 92-97.

Bjorck I, Liljeberg H \& Ostman E (2000) Low glycaemic-index foods. Br J Nut 83, Suppl. 1, S149-S155.

Borg GA (1973) Perceived exertion: a note on "history" and methods. Med Sci Sports 5, 90-93.

Burke LM, Collier GR, Beasley SK, et al. (1995) Effect of coingestion of fat and protein with carbohydrate feedings on muscle glycogen storage. J Appl Physiol 78, 2187-2192.

Coulston AM, Hollenbeck CB, Liu GC, et al. (1984a) Effect of source of dietary carbohydrate on plasma glucose, insulin, and gastric inhibitory polypeptide responses to test meals in subjects with noninsulin-dependent diabetes mellitus. Am J Clin Nutr 40, 965-970.

Coulston AM, Hollenbeck CB \& Reaven GM (1984b) Utility of 
studies measuring glucose and insulin responses to various carbohydrate-containing foods. Am J Clin Nutr 39, 163-167.

Coyle EF, Jeukendrup AE, Wagenmakers AJ \& Saris WH (1997) Fatty acid oxidation is directly regulated by carbohydrate metabolism during exercise. Am J Physiol 273, E268-E275.

Decombaz DS, Arnaud MJ, Thelin AL, Schurch P \& Howald H (1985) Oxidation and metabolic effects of fructose or glucose ingested before exercise. Int J Sports Med 6, 282-286.

DeMarco HM, Sucher KP, Cisar CJ \& Butterfield GE (1999) Preexercise carbohydrate meals: application of glycemic index. Med Sci Sports Exerc 31, 164-170.

Dill DB \& Costill DL (1974) Calculation of percentage changes in volumes of blood, plasma, and red cells in dehydration. $J$ Appl Physiol 37, 247-248.

Febbraio MA, Chiu A, Angus DJ, Arkinstall MJ \& Hawley JA (2000a) Effects of carbohydrate ingestion before and during exercise on glucose kinetics and performance. J Appl Physiol 89, 2220-2226.

Febbraio MA, Keenan J, Angus DJ, Campbell SE \& Garnham AP (2000b) Preexercise carbohydrate ingestion, glucose kinetics, and muscle glycogen use: effect of the glycemic index. $J$ Appl Physiol 89, 1845-1851.

Febbraio MA \& Stewart KL (1996) CHO feeding before prolonged exercise: effect of glycemic index on muscle glycogenolysis and exercise performance. $J$ Appl Physiol 81, 1115-1120.

Fielding RA, Costill DL, Fink WJ, King DS, Kovaleski JE \& Kirwan JP (1987) Effects of pre-exercise carbohydrate feedings on muscle glycogen use during exercise in well-trained runners. Eur J Appl Physiol Occup Physiol 56, 225-229.

Foster-Powell K \& Miller JB (1995) International table of glycaemic index. Am J Clin Nutr 62, 871S-890S.

Frayn KN (1983) Calculation of substrate oxidation rates in vivo from gaseous exchange. $J$ Appl Physiol 55, 628-634.

Hargreaves M, Costill DL, Fink WJ, King DS \& Fielding RA (1987) Effect of pre-exercise carbohydrate feedings on endurance cycling performance. Med Sci Sports Exerc 19, 33-36.

Hollenbeck CB, Coulston AM \& Reaven GM (1988) Comparison of plasma glucose and insulin responses to mixed meals of high-, intermediate-, and low-glycemic potential. Diabetes Care 11, 323-329.

Horowitz JF, Mora-Rodriguez R, Byerley LO \& Coyle EF (1997) Lipolytic suppression following carbohydrate ingestion limits fat oxidation during exercise. Am J Physiol 273, E768-E775.

Ivy JL, Lee MC, Brozinick JT Jr \& Reed MJ (1988) Muscle glycogen storage after different amounts of carbohydrate ingestion. J Appl Physiol 65, 2018-2023.

Jenkins DJ, Wolever TM, Taylor RH et al. (1981) Glycemic index of foods: a physiological basis for carbohydrate exchange. Am J Clin Nutr 34, 362-366.

Kirwan JP, Cyr-Campbell D, Campbell WW, Scheiber J \& Evans WJ (2001a) Effects of moderate and high glycemic index meals on metabolism and exercise performance. Metab Clin Exp 50, $849-855$

Kirwan JP, O'Gorman DJ, Cyr-Campbell D, Campbell WW, Yarasheski KE \& Evans WJ (2001b) Effects of a moderate glycemic meal on exercise duration and substrate utilization. Med Sci Exerc 33, 1517-1523.

Laurell S \& Tibbling G (1966) An enzymatic fluorometric micromethod for the determination of glycerol. Clin Chim Acta 13, 317-322.

Maughan RJ (1982) A simple, rapid method for the determination of glucose, lactate, pyruvate, alanine, 3-hydroxybutyrate and acetoacetate on a single 20- $\mu$ l blood sample. Clin Chim Acta 122, 231-240.

Murray R, Paul GL, Seifert JG, Eddy DE \& Halaby GA (1989a) The effects of glucose, fructose, and sucrose ingestion during exercise. Med Sci Sports Exerc 21, 275-282.

Murray R, Seifert JG, Eddy DE, Paul GL \& Halaby GA (1989b) Carbohydrate feeding and exercise: effect of beverage carbohydrate content. Eur J Appl Physiol Occup Physiol 59, $152-158$.

Nilsson LH \& Hultman E (1973) Liver glycogen in man - the effect of total starvation or a carbohydrate-poor diet followed by carbohydrate refeeding. Scand J Clin Lab Invest 32, 325-330.

Sparks MJ, Selig SS \& Febbraio MA (1998) Pre-exercise carbohydrate ingestion: effect of the glycemic index on endurance exercise performance. Med Sci Sports Exerc 30, 844-849.

Stannard SR, Constantini NW \& Miller JC (2000) The effect of glycemic index on plasma glucose and lactate levels during incremental exercise. Int J Sport Nutr Exerc Metab 10, 51-61.

Tarnopolsky MA, Bosman M, Macdonald JR, Vandeputte D, Martin J \& Roy BD (1997) Postexercise protein-carbohydrate and carbohydrate supplements increase muscle glycogen in men and women. J Appl Physiol 83, 1877-1883.

Thomas DE, Brotherhood JR \& Brand JC (1991) Carbohydrate feeding before exercise: effect of glycemic index. Int $J$ Sports Med 12, 180-186.

Thomas DE, Brotherhood JR \& Miller JB (1994) Plasma glucose levels after prolonged strenuous exercise correlate inversely with glycemic response to food consumed before exercise. Int J Sport Nutr 4, 361-373.

Ventura JL, Estruch A, Rodas G \& Segura R (1994) Effect of prior ingestion of glucose or fructose on the performance of exercise of intermediate duration. Eur J Appl Physiol Occup Physiol 68, 345-349.

Wee SL, Williams C, Gray S \& Horabin J (1999) Influence of high and low glycemic index meals on endurance running capacity. Med Sci Sports Exerc 31, 393-399.

Williams C, Nute MG, Broadbank L \& Vinall S (1990) Influence of fluid intake on endurance running performance. A comparison between water, glucose and fructose solutions. Eur J Appl Physiol Occup Physiol 60, 112-119.

Wolever TM \& Bolognesi C (1996) Prediction of glucose and insulin responses of normal subjects after consuming mixed meals varying in energy, protein, fat, carbohydrate and glycemic index. $J$ Nutr 126, 2807-2812.

Wolever TM \& Jenkins DJ (1986) The use of the glycemic index in predicting the blood glucose response to mixed meals. Am J Clin Nutr 43, 167-172. 